\title{
Age-Related Deterioration of Rod Vision in Mice
}

\author{
Alexander V. Kolesnikov, ${ }^{1}$ Jie Fan, ${ }^{2}$ Rosalie K. Crouch, ${ }^{2}$ and Vladimir J. Kefalov ${ }^{1}$ \\ ${ }^{1}$ Department of Ophthalmology and Visual Sciences, Washington University School of Medicine, Saint Louis, Missouri 63110, and ${ }^{2}$ Department of \\ Ophthalmology, Medical University of South Carolina, Charleston, South Carolina 29425
}

Even in healthy individuals, aging leads to deterioration in visual acuity, contrast sensitivity, visual field, and dark adaptation. Little is known about the neural mechanisms that drive the age-related changes of the retina and, more specifically, photoreceptors. According to one hypothesis, the age-related deterioration in rod function is due to the limited availability of 11-cis-retinal for rod pigment formation. To determine how aging affects rod photoreceptors and to test the retinoid-deficiency hypothesis, we compared the morphological and functional properties of rods of adult and aged B6D2F1/J mice. We found that the number of rods and the length of their outer segments were significantly reduced in 2.5-year-old mice compared with 4-month-old animals. Aging also resulted in a twofold reduction in the total level of opsin in the retina. Behavioral tests revealed that scotopic visual acuity and contrast sensitivity were decreased by twofold in aged mice, and rod ERG recordings demonstrated reduced amplitudes of both a- and b-waves. Sensitivity of aged rods determined from single-cell recordings was also decreased by 1.5 -fold, corresponding to not more than $1 \%$ free opsin in these photoreceptors, and kinetic parameters of dim flash response were not altered. Notably, the rate of rod dark adaptation was unaffected by age. Thus, our results argue against age-related deficiency of 11-cis-retinal in the B6D2F1/J mouse rod visual cycle. Surprisingly, the level of cellular dark noise was increased in aged rods, providing an alternative mechanism for their desensitization.

\section{Introduction}

Psychophysical and physiological studies in humans have demonstrated that a number of rod-mediated visual functions are compromised with age. Among them are age-related decrease in rod-driven, or scotopic, visual acuity and spatial contrast sensitivity (Adams et al., 1988; Sloane et al., 1988; HaegerstromPortnoy et al., 1999) and scotopic flash sensitivity (Birch and Anderson, 1992; Jackson et al., 1998; Jackson and Owsley, 2000). In addition, in elder humans ( $>60$ years of age) with no visible retinal pathology, the inactivation phase of the photoresponse to light under scotopic conditions is somewhat slower than in 20- to 30-year-old individuals (Jackson et al., 2006). Finally, aged patients experience delayed rod dark adaptation (Steinmetz et al., 1993; Jackson et al., 1999).

Considering the dramatic effects of the loss of vision on quality of life at old age, surprisingly little is known about the molecular changes that occur in rods with age. Specifically, it is not known how aging affects the regeneration of their visual pigment. Restoration of the photoactivated, or bleached, rhodopsin to its

\footnotetext{
Received Aug. 27, 2009; revised July 1, 2010; accepted July 7, 2010.

This work was supported by a Career Development Award from Research to Prevent Blindness and grants from the International Retina Research Foundation and the Karl Kirchgessner Foundation (V.J.K.), unrestricted grants from Research to Prevent Blindness to the Departments of Ophthalmology and Visual Sciences at Washington University and the Medical University of South Carolina, and National Institutes of Health Grants EY019312 (V.J.K.), EY004939 (R.K.C.), and EY002687 to the Department of Ophthalmology and Visual Sciences at Washington University. We are grateful to Krikor Dikranian, Jean Jones, and Belinda McMahan for their advice and help with the morphometric analysis, to Frank Schottler for his help with TEM, to Nancy Nadon from the National Institute on Aging for the access to aged mice, and to Alapakkam Sampath for his comments on the manuscript.

Correspondence should be addressed to Dr. Alexander V. Kolesnikov, Department of Ophthalmology and Visual Sciences, Washington University in Saint Louis, 660 South Euclid Avenue, Saint Louis, M0 63110. E-mail: kolesnikov@wustl.edu.

DOI:10.1523/JNEUROSCI.4239-09.2010

Copyright $\odot 2010$ the authors $\quad 0270-6474 / 10 / 3011222-10 \$ 15.00 / 0$
}

previous dark state, a crucial component of dark adaptation, is achieved in a complex chain of biochemical reactions called the visual cycle (for review, see Thompson and Gal, 2003; Lamb and Pugh, 2004). The reactions of the rod visual cycle proceed in both rod outer segments and adjacent cells of retinal pigment epithelium (RPE) and include the decay of rhodopsin into apo-opsin and all-trans-retinal, the reduction of all-trans-retinal to alltrans-retinol, its subsequent transport to the RPE, followed by conversion into 11-cis-retinal, and the transport of 11-cischromophore back to photoreceptors, where it finally recombines with free opsin to form functional visual pigment.

According to one hypothesis, the age-related deterioration in rod function in humans could be due to the limited availability of 11-cis-retinal caused either by defects in the processing of retinoids in the RPE or within photoreceptors (Jackson et al., 2002). This retinoid deficiency would result in accumulation of constitutively active free opsin in aged rods, providing their significant desensitization (Cornwall and Fain, 1994) and would also explain the delayed dark adaptation in aged patients. Here, we tested the retinoid deficiency hypothesis in mice by investigating how aging affects the morphology, opsin levels, and electrophysiological properties of rods of hybrid B6D2F1/J mice, chosen for their availability and increased lifespan (29-32 months) over the traditionally used C57BL/6J (27-28 months) and DBA/2J (23-27 months) inbred strains from which they were derived (Turturro et al., 1999; Nadon, 2006).

\section{Materials and Methods}

Animals. All mice used in this study were females of B6D2F1/J strain; 3to 4-month-old animals were purchased from Jackson Laboratories and 2.5-year-old animals were purchased from the National Institute on Aging. This strain is a F1 hybrid between two pigmented strains, C57BL/6J females and DBA/2J males, and has the advantage of improved viability at 
old age compared with nonhybrid strains. All animals were maintained under 12/12 h light/dark cycle and dark adapted overnight before experiments. All experiments were performed in accordance with the policy on the Use of Animals in Neuroscience Research and were approved by the Washington University Animal Studies Committee and the Medical University of South Carolina Animal Care and Use Committee.

Visual acuity and contrast sensitivity measured from optomotor responses. Spatial contrast visual sensitivity in 4-month-old and 2.5-yearold mice was measured using a two-alternative forced-choice protocol (Umino et al., 2008). The optomotry system (CerebralMechanics) consisted of a square array of four computer monitors and had a pedestal in the center where the mouse was placed. An infrared-sensitive television camera (Sony) was mounted above the animal to allow observation of the mouse but not the monitors. To visualize the animal, a round array of six infrared LEDs (F5D series; Fairchild Semiconductor) was mounted to the top lid of the system. Using the staircase paradigm (Umino et al., 2008), rotating stimuli (sine-wave vertical gratings) were applied on the monitors, where they formed a virtual cylinder around the mouse (Prusky et al., 2004). The direction of the gratings' movement for each $5 \mathrm{~s}$ trial was randomly selected by the computer-controlled protocol. Mice responded to the stimuli by reflexively rotating their head in the corresponding direction. The observer registered either the presence of the mouse head motion (in clockwise or counterclockwise direction) or its absence. Based on observer's responses and using the staircase paradigm, the computer protocol changed the gratings contrast (in the contrast sensitivity measuring mode) or spatial frequency (in the visual acuity measuring mode) until reaching the threshold, defined as the presence of mouse responses in 70\% trials (Umino et al., 2008). Optomotor responses were measured under two background light conditions: scotopic $\left(-4.45 \log \mathrm{cd} \mathrm{m}^{-2}\right)$ or photopic $\left(1.85 \log \mathrm{cd} \mathrm{m}^{-2}\right)$. For scotopic conditions, background monitor luminance was controlled by neutral density film filters (E-Color no. 211 0.9 ND; Rosco Laboratories).

For contrast sensitivity measurements, temporal frequency $\left(F_{\mathrm{t}}\right)$ was fixed at its optimal values of 0.8 and $1.5 \mathrm{~Hz}$ for scotopic and photopic conditions, respectively. Spatial frequency $\left(F_{\mathrm{s}}\right)$ was set at $0.128 \mathrm{cyc} / \mathrm{deg}$ (close to its optimum) for both conditions, and the speed of the stimuli $\left(S_{\mathrm{p}}\right)$ was 6.3 and $12.0 \mathrm{deg} / \mathrm{s}$, correspondingly. Starting at 100\%, the contrast was gradually decreased by the computer protocol until reaching threshold. Contrast sensitivity was defined as the inverse of contrast threshold for optomotor responses.

Visual acuity was defined as the threshold for spatial frequency of gratings with $100 \%$ contrast and measured at the optimal speed [set at $12.0 \mathrm{deg} / \mathrm{s}$, as adopted from Umino et al. (2008) and confirmed by us]. In this mode, $F_{\mathrm{s}}$ was gradually increased by the computer protocol (starting from $0.128 \mathrm{cyc} / \mathrm{deg}$ ) until its threshold was determined. $F_{\mathrm{t}}$ was automatically adjusted by the computer program, based on the following equation: $F_{\mathrm{t}}=S_{\mathrm{p}} \cdot F_{\mathrm{s}}$ (Umino et al., 2008).

Morphometric analysis. Four-month-old and 2.5-year-old animals were killed by $\mathrm{CO}_{2}$ asphyxiation and eyes were enucleated and immersion-fixed for $24 \mathrm{~h}$ in PBS, pH 7.4, containing $2 \%$ glutaraldehyde and $2 \%$ paraformaldehyde at $4^{\circ} \mathrm{C}$. After a few hours of dehydration, eyecups from both eyes were embedded in an Epon-Araldite mixture and $1 \mu \mathrm{m}$ sections were cut serially dorsal to ventral through the optic nerve and stained with toluidine blue (Rohrer et al., 2001). Starting from the corresponding edge of the optic nerve head, seven dorsal and seven ventral locations $(193 \times 145 \mu \mathrm{m})$ of each stained retina section were photographed for analysis, with a step of $0.36 \mathrm{~mm}$ between them. Cell nuclei of the outer nuclear layer (ONL) were manually counted in the central 66 $\mu \mathrm{m}$ region of each location and expressed as a number per $50 \mu \mathrm{m}$ of the ONL layer. In addition, rod outer segment (ROS) length and ONL thickness were measured in the same $66 \mu \mathrm{m}$ regions (averaged from five to six measurements in different parts of each area). Four to five $1 \mu \mathrm{m}$ sections per mouse (two to three from each eyecup) were analyzed. In total, 14 sections (with 14 locations per section, see above) were analyzed per group of three animals of each age.

Transmission electron microscopy (TEM) was performed as follows. Both superior and inferior portions of the retina were chosen for TEM sampling after evaluating previously taken, adjacent, semithin sections. This was necessary to maximize the sampling of circular or slightly oblique ROS profiles, rather than longitudinal sections of ROS profiles, since the orientation of ROS profiles exhibited a large variability across the retina in individual samples. Blocks were trimmed to include 1000 $\mu \mathrm{m}$ retinal length, starting $\sim 500 \mu \mathrm{m}$ lateral to the optic nerve. Ultrathin $(0.05 \mu \mathrm{m})$ sections of retina were picked up on Formvar-coated $1 \times 2$ slot grids and stained with uranyl acetate and lead citrate. Nonoverlapping $18.3 \times 21.1 \mu \mathrm{m}$ micrographs $(8-13$ per animal) of areas containing mainly cross-sectional or oblique ROS profiles were taken from each single section at $8000 \times$ magnification using Hitachi H7500 electron microscope. Only images with prevailing circular or slightly oblique profiles (containing 70-110 cells per image) were chosen for analysis of ROS diameter. The minimal diameters of ROS profiles for three animals in the 4-month-old (2335 profiles) and 2.5-year-old (2134 profiles) age groups were measured. All measurements for light microscopy and TEM were obtained with imaging analysis software (ImageJ $1.40 \mathrm{~g}$ ).

Opsin quantification. Retinae from dark-adapted adult and aged mice were collected under infrared illumination and samples were prepared as reported previously (Rohrer et al., 2003). Briefly, two retinae from each animal were homogenized with a glass syringe in $200 \mu \mathrm{l}$ of $10 \mathrm{~mm}$ Tris$\mathrm{HCl}$ containing $1 \mathrm{~mm}$ EDTA, pH 7.5, 1 mm 4-(2-aminoethyl)-benzene sulfonyl fluoride hydrochloride (Roche Molecular Biochemicals), protease inhibitor mixture ( 1 tablet/10 ml; Complete Mini; Roche Molecular Biochemicals), and $10 \mu \mathrm{g}$ of DNase I (Sigma). Samples were centrifuged $(27,000 \times g, 15 \mathrm{~min})$ and the supernatant discarded. For regeneration, pellets were resuspended in $100 \mu \mathrm{l}$ of $0.1 \mathrm{M}$ sodium phosphate buffer, $\mathrm{pH}$ 7.4, containing $8 \mathrm{nmol}$ of 11-cis-retinal in ethanol (final concentration, $1 \%$ ) and gently stirred at $4^{\circ} \mathrm{C}$ for $2 \mathrm{~h}$. Samples were centrifuged and the resultant pellets were resuspended in $100 \mu \mathrm{l}$ of $1 \% \mathrm{~N}$-dodecyl- $\beta$-Dmaltoside (ULTROL grade; Calbiochem) in $0.1 \mathrm{~m}$ sodium phosphate buffer, $\mathrm{pH} 7.4$, for solubilization $\left(2 \mathrm{~h}, 4^{\circ} \mathrm{C}\right.$, on a rotator). Unsolubilized material was removed by centrifugation $(100,000 \times g$ for $15 \mathrm{~min})$, and the supernatant was analyzed using a Cary 300 spectrophotometer (Varian). Samples were exposed to white light (Fiber Optic Illuminator, Model 190, $50 \mathrm{~W}, 60 \mathrm{~Hz}$; Dolan-Jenner Industries) for $10 \mathrm{~min}$ in the presence of freshly neutralized hydroxylamine hydrochloride $(\mathrm{pH} 7.0$, final concentration $20 \mathrm{~mm}$ ). To determine pigment levels, postbleach spectra were subtracted from the prebleach spectra and rhodopsin concentrations were calculated using the extinction coefficient of 40,000 $\mathrm{M}^{-1} \mathrm{~cm}^{-1}$ (Wald and Brown, 1958; Dartnall, 1968).

Electroretinography. Dark-adapted mice were anesthetized with a hypodermic injection of a mixture of ketamine $(100 \mathrm{mg} / \mathrm{kg})$ and xylazine (20 mg/kg). Pupils were dilated with $1 \%$ atropine sulfate. Mouse body temperature was maintained at $37^{\circ} \mathrm{C}$ with a passive-heating pad. Scotopic ERG responses were measured from both eyes using contact corneal platinum-ring electrodes held in place by a drop of Gonak solution. Full-field ERGs were recorded with the UTAS-E 3000 system (LKC Technologies), using $10 \mu$ s Ganzfeld-derived pulse stimuli of calibrated white light intensity. The amplitude of the a-wave was measured from the baseline to the primary peak of negative polarity voltage. The amplitude of b-wave was determined from the a-wave peak to the maximum of the secondary positive peak. Up to 30 measurements were averaged at lower light intensities. To avoid significant bleaching of the visual pigment, as few as three to five measurements were averaged at higher light intensities, with increased time intervals (up to $2-3 \mathrm{~min}$ ) between them. Cone recordings were made under room illumination $\left(25 \mathrm{~cd} \cdot \mathrm{s} \mathrm{m}^{-2}\right)$ after 5 min of light adaptation.

In experiments designed to determine the rate of recovery of ERG a-wave amplitude and sensitivity after $1 \mathrm{~min}$ exposure to light bleaching $>90 \%$ of rod pigment (delivered by $520 \mathrm{~nm}$ LED focused at the surface of mouse eye cornea and producing $\sim 2.5 \times 10^{8}$ photons $\mu \mathrm{m}^{-2}$ $\left.\mathrm{s}^{-1}\right)$, mice were reanesthetized every $30-40 \mathrm{~min}$ with a small doze of ketamine $(\sim 1 / 4$ of the initial doze). A 1:1 mixture of PBS and Gonak solutions was gently applied to the eyes using a plastic syringe to protect them from drying and to maintain electrode contacts. In addition, every $1 \mathrm{~h}$ a drop of $1 \%$ atropine sulfate was added to the eye surface to keep pupils dilated.

Single-cell electrophysiology. Single-cell recordings of mouse rod outer segment membrane currents were performed as described previously (Shi et al., 2007). Briefly, mice were killed by $\mathrm{CO}_{2}$ asphyxiation and 
Table 1. Visual acuity and spatial contrast sensitivity in adult and aged B6D2F1/J mice

\begin{tabular}{llcc}
\hline & Adult mice (4-month-old) & Aged mice (2.5-year-old) & $p$ value \\
\hline Scotopic visual acuity, cyc/deg & $0.43 \pm 0.01(n=6)$ & $0.23 \pm 0.01(n=6)$ & $<0.001$ \\
Scotopic spatial contrast sensitivity & $10.3 \pm 0.3(n=6)$ & $5.9 \pm 0.5(n=6)$ & $<0.001$ \\
Photopic visual acuity, cyc/deg & $0.46 \pm 0.003(n=6)$ & $0.45 \pm 0.01(n=6)$ & 0.58 \\
Photopic spatial contrast sensitivity & $17.1 \pm 0.7(n=6)$ & $18.6 \pm 2.0(n=6)$ & 0.50 \\
\hline
\end{tabular}

Data were derived from mouse optomotor responses to rotating gratings, under both scotopic $\left(-4.45 \log \mathrm{cd} \mathrm{m}^{-2}\right)$ and photopic $\left(1.85 \log \mathrm{cd} \mathrm{m}^{-2}\right)$ background illumination conditions. See Materials and Methods for details. Values are means \pm SEM.

retinae removed from eyecups under infrared illumination. Retinae were chopped into small pieces with a razor blade. Retinal pieces were transferred to perfusion chamber on the stage of inverted microscope. A single rod outer segment was drawn into a glass microelectrode filled with solution containing the following (in $\mathrm{mM}$ ): $140 \mathrm{NaCl}, 3.6 \mathrm{KCl}, 2.4 \mathrm{MgCl}_{2}, 1.2$ $\mathrm{CaCl}_{2}, 3$ HEPES, pH 7.4, 0.02 EDTA, and 10 glucose. The solution used for cell perfusion contained the following (in $\mathrm{mm}$ ): $112.5 \mathrm{NaCl}$, $3.6 \mathrm{KCl}, 2.4 \mathrm{MgCl}_{2}, 1.2 \mathrm{CaCl}_{2}, 10$ HEPES, $\mathrm{pH}$ 7.4, $20 \mathrm{NaHCO}_{3}, 3 \mathrm{Na}$ succinate, $0.5 \mathrm{Na}$ glutamate, 0.02 EDTA, and 10 glucose. The perfusion solution was continuously bubbled with $95 \%$ $\mathrm{O}_{2} / 5 \% \mathrm{CO}_{2}$ mixture and heated to $36-38^{\circ} \mathrm{C}$.

Light stimulation was applied by $20 \mathrm{~ms}$ test flashes of calibrated $500 \mathrm{~nm}$ light. The stimulating light intensity was controlled by neutral density filters in 0.5 log unit steps. In experiments designed to monitor the recovery of rod dark current and sensitivity after bleaching, $12 \%$ of the rod visual pigment was bleached with a $3.5 \mathrm{~s}$ step of $500 \mathrm{~nm}$ light. The bleach fraction was estimated from the relation: $F=$ $1-\exp (-I P t)$, where $F$ is the fraction of pigment bleached, $I$ is the bleaching light intensity of not-attenuated $500 \mathrm{~nm}$ light $\left(6.4 \times 10^{6}\right.$ photons $\mu \mathrm{m}^{-2} \mathrm{~s}^{-1}$ ), and $P$ is the photosensitivity of mouse rod at the wavelength of peak absorbance $\left(5.7 \times 10^{-9} \mu \mathrm{m}^{2}\right)$, adopted from Woodruff et al. (2004). The same equation was used to estimate $1 \%$ fraction of bleached rhodopsin (with a $275 \mathrm{~ms}$ light step) in experiments aimed to address the origin of cellular dark noise and change of sensitivity in aged rods. Photoresponses were amplified, lowpass filtered at $30 \mathrm{~Hz}$ (8-pole Bessel), digitized at $1 \mathrm{kHz}$, and stored on a computer for further analysis. Flash sensitivity $\left(S_{\mathrm{f}}\right)$ was calculated from the linear region of the intensity-response curve as the ratio of response amplitude and flash strength. Half-saturating light intensity $\left(I_{1 / 2}\right)$ was calculated from the intensity-response relation for each cell as the test flash intensity required to produce a response with an amplitude equal to half of the corresponding saturated response amplitude. Integration time $\left(T_{\text {integr }}\right)$ was calculated as the integral of the dim flash response with the transient peak amplitude normalized to unity. The time constant of the $\operatorname{dim}$ flash response recovery $\left(\tau_{\text {rec }}\right)$ was derived from single-exponential fit to the falling phase of the response. Single-photon response amplitude (a) was calculated from the ensemble variance-to-mean ratio of $50 \mathrm{dim}$ flash responses from the linear range and not exceeding $20 \%$ of the saturated response amplitude (Baylor et al., 1979). Data were analyzed using Clampfit 10.2 and Origin 7.5 software.

For measurements of cellular dark noise, membrane currents (sets of 50 $3.5 \mathrm{~s}$ sweeps for each cell) were recorded in darkness. The dark power spectrum was calculated from individual traces and averaged over the set for each cell and finally across cells. The total cellular dark noise variance was determined for each cell by integrating the power spectrum over the bandwidth $0.4-10 \mathrm{~Hz}$ and averaged over all cells. In experiments of background light adaptation, both cellular noise and sensitivity were measured for each cell under each background light condition.
Application of exogenous 11-cis-retinal to aged rods was performed as follows: $300 \mu \mathrm{g}$ of dried retinoid was dissolved in $5 \mu \mathrm{l}$ of ethanol and diluted to $8 \mathrm{ml}$ with electrode solution containing 1\% BSA, to achieve final retinoid concentration of $\sim 130 \mu \mathrm{M}$. Before transferring to the perfusion chamber, the rod suspension was incubated in this solution for 10-15 min at room temperature.

Statistics. For all experiments, data were expressed as mean \pm SEM. Data were analyzed using independent two-tailed Student's $t$ test, with accepted significance level of $p<0.05$.

\section{Results}

Scotopic visual dysfunction in aged mice

To characterize the effect(s) of normal aging on mouse vision, we initially performed behavioral tests based on the ability of mice to reflexively track computer-generated rotating sine-wave gratings (Prusky et al., 2004). The optomotor response thresholds can be plotted as contrast sensitivity functions (CSFs) that have characteristic bandpass or low-pass profiles and are tuned to stimulus temporal frequency and speed under photopic and scotopic conditions, respectively (Umino et al., 2008). However, it was difficult to obtain complete CSFs for aged mice in long-lasting experiments of this sort, due to their rapid fatigue and behavioral inactivity. Therefore, to reliably determine the differences in spa- 
Table 2. Morphological parameters and opsin levels in retinae of adult and aged B6D2F1/J mice

\begin{tabular}{|c|c|c|c|}
\hline & Adult mice (4-month-old) & Aged mice (2.5-year-old) & $p$ value \\
\hline ONL thickness, $\mu \mathrm{m}$ & $29.4 \pm 0.5$ ( $n=196 ; 3$ mice $)$ & $25.1 \pm 0.4$ ( $n=196 ; 3$ mice $)$ & $<0.001$ \\
\hline Rod nuclei, per $50 \mu \mathrm{m}$ & $98.5 \pm 1.7$ ( $n=196 ; 3$ mice $)$ & $78.4 \pm 1.4$ ( $n=196 ; 3$ mice $)$ & $<0.001$ \\
\hline ROS length, $\mu \mathrm{m}$ & $21.3 \pm 0.2(n=196 ; 3$ mice $)$ & $19.3 \pm 0.3$ ( $n=196 ; 3$ mice $)$ & $<0.001$ \\
\hline ROS diameter, $\mu \mathrm{m}$ & $1.53 \pm 0.01$ ( $n=2335 ; 3$ mice $)$ & $1.46 \pm 0.01$ ( $n=2134 ; 3$ mice $)$ & $<0.001$ \\
\hline Opsin level, pmol/retina & $472.5 \pm 19.3(n=4)$ & $230.7 \pm 38.2(n=4)$ & $<0.002$ \\
\hline
\end{tabular}

Data from light microscopy were averaged across all 14 analyzed retina locations ( 7 dorsal and 7 ventral). ROS diameter was measured by TEM in ultrathin cross-sections, including $1000 \mu \mathrm{m}$ of retinal length, starting approximately $500 \mu \mathrm{m}$ lateral to the optic nerve. The total number of measured profiles is given. Values are means \pm SEM.

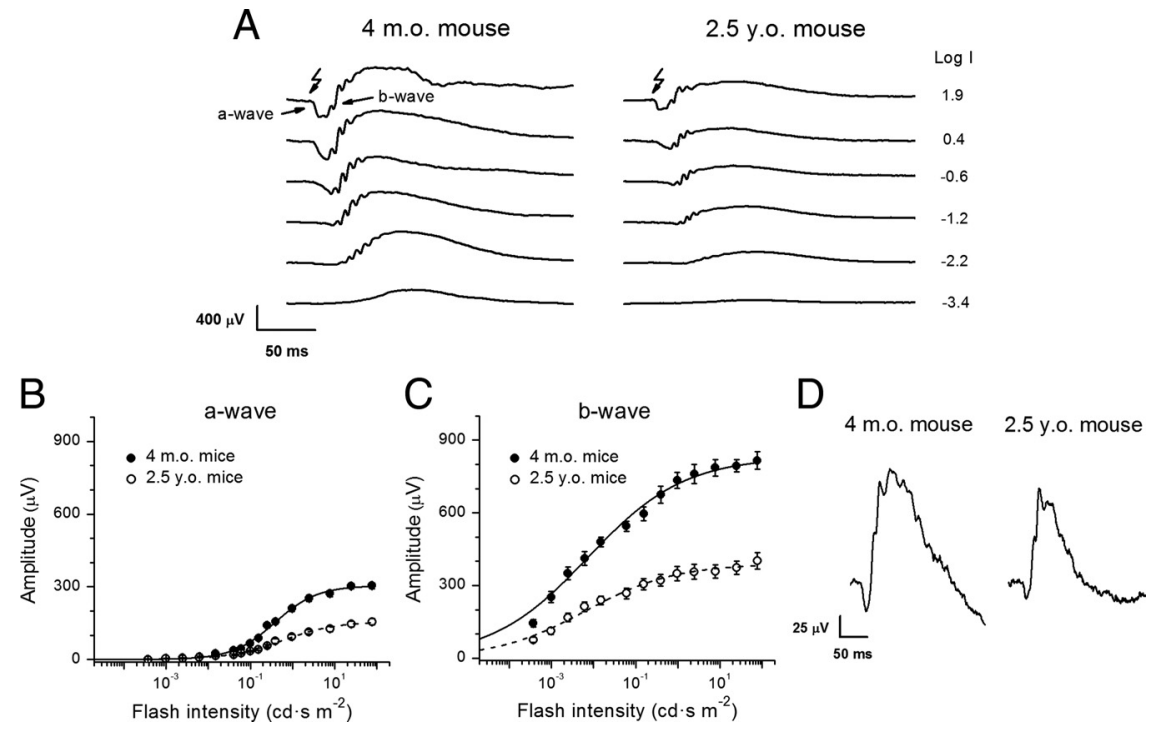

Figure 2. Analysis of ERG responses in 4-month-old and 2.5-year-old mice. $\boldsymbol{A}$, Representative families of scotopic ERG recordings from adult (left) and aged (right) mice evoked by white light flashes of increasing intensities, indicated to the right of the traces as the $\log$ intensity (in $\left.\mathrm{cd} \cdot \mathrm{s} \cdot \mathrm{m}^{-2}\right) . \boldsymbol{B}, \boldsymbol{C}$, Amplitudes of scotopic ERG a- $(\boldsymbol{B})$ and b- $(\boldsymbol{C})$ waves plotted versus flash intensity. Averaged data from both eyes of six or seven animals of each age group. Values are means \pm SEM. The data were fitted by hyperbolic functions (Fulton and Rushton, 1978), as follows:

$$
A=A_{\max } \frac{I^{\mathrm{n}}}{I^{\mathrm{n}}+I_{\mathrm{h}}^{\mathrm{n}}},
$$

where $A_{\max }$ is the maximal amplitude, I is the flash intensity, $\mathrm{n}$ is the Hill coefficient, and $I_{\mathrm{h}}$ is the half-saturating light intensity. Fitting parameters are summarized in Table 3. D, Population-averaged photopic ERG responses from adult (left) and aged (right) mice evoked by white light flashes $\left(2.7 \log \mathrm{cd} \cdot \mathrm{s} \cdot \mathrm{m}^{-2}\right.$ ). Amplitudes of cone ERG a-waves are $39 \pm 4 \mu \mathrm{V}$ (adult mice, $\left.n=4\right)$ and $26 \pm 3 \mu \mathrm{V}$ (aged mice, $n=4$ ), and amplitudes of cone b-waves are $191 \pm 15 \mu \mathrm{V}$ (adult mice, $n=4$ ) and $149 \pm 16 \mu \mathrm{V}$ (aged mice, $n=4)$. The $p$ values are $<0.05$ for both parameters.

tial contrast sensitivity between the two age groups under both scotopic and photopic conditions, we limited our experiments to the optimal fixed spatial $(0.128 \mathrm{cyc} / \mathrm{deg})$ and temporal $(0.8 \mathrm{~Hz}$ for scotopic or $1.5 \mathrm{~Hz}$ for photopic conditions) frequencies, determined in preliminary experiments and consistent with previous results (Umino et al., 2008).

We found that under photopic conditions, both visual acuity and spatial contrast sensitivity in B6D2F1/J mice were unaffected by age (Table 1). This result is consistent with the minimal changes in number of cone photoreceptors in pigmented C57BL/6 mouse retinae (Gresh et al., 2003) and indicates that cone function was not significantly affected in the aged B6D2F1/J mice. In contrast, under scotopic conditions, both visual acuity and contrast sensitivity were decreased by up to $50 \%$ in aged mice compared with 4-month-old animals (Table 1), demonstrating significant deterioration of rod-mediated visual function.

\section{Impaired viability of aged-mouse rods}

To determine the possible reason(s) for the decline in scotopic sensitivity, we first analyzed retinal morphology in 4-month-old and 2.5-year-old B6D2F1/J mice (Fig. 1, Table 2). The number of photoreceptor nuclei (per $50 \mu \mathrm{m}$ ONL layer) varied depending on the location within the retina, being larger at the central area and gradually declining toward the retina periphery (Fig. $1 B$ ). The average length of ROS in 4-month-old B6D2F1/J mouse retinae $(21.3 \pm 0.2 \mu \mathrm{m})$ was comparable to that reported earlier for a number of other mouse strains (Gresh et al., 2003; Daniele et al., 2005). However, in aged mice, the average number of photoreceptor nuclei was reduced by $\sim 20 \%(p<0.001)$ and the average ROS length was decreased by $\sim 10 \%$ ( $p<0.001$ ) (Table 2). Interestingly, we found that the ventral part of the mouse retina was more vulnerable to photoreceptor loss (Fig. 1 B). The distribution of the ONL layer thickness followed the number of photoreceptor nuclei (data not shown) and, in aged retinae of B6D2F1/J mice, this parameter was reduced, on average, by $\sim 15 \%(p<0.001)$ (Table 2$)$. This finding is in general agreement with previously published results on other mouse strains (Gresh et al., 2003) and rats (Cunea and Jeffery, 2007). The apparent slight discrepancy between the age-related reduction in number of nuclei and ONL thickness could be due to increased size and disorganization of the photoreceptor nuclei in aged B6D2F1/J mouse retinae.

By using TEM, we found that the diameter of aged ROS determined in the ROS cross-sections (Fig. $1 C$ ) was, on average, $\sim 4.3 \%$ smaller than in ROS of adult B6D2F1/J mice $(p<0.001)$ (Fig. $1 D$, Table 2), although the latter estimate was somewhat larger in our measurements $(1.53 \pm 0.01 \mu \mathrm{m})$ compared with that reported for different mouse strains $(\sim 1.3-1.4 \mu \mathrm{m})$ (Carter-Dawson and LaVail, 1979; Wen et al., 2009). Combined with the shortening of the outer segments, this change would yield $\sim 18 \%$ smaller average outersegment volume in aged photoreceptors. Combining the decreased outer segment volume of aged rods and lower density of photoreceptor nuclei, we estimated the overall loss of ROS material in 2.5year-old B6D2F1/J mice to be $\sim 40 \%$, consistent with earlier data obtained by others (Gresh et al., 2003). This reduction was in a reasonable agreement with the observed 50\% decrease in the total level of apo-protein opsin in retinae of old animals (Table 2). The apparent discrepancy between the two numbers is likely within the experimental error of these measurements. Both rod photoreceptor loss and decline in opsin levels were intermediate in 18- to 20-month-old animals (data not shown). 
To determine how age-related reduction in quantum catch due to the smaller number and size of rod photoreceptors affects the ability of the retina to respond to light, we performed transcorneal ERG recordings from adult and aged animals. Figure $2 \mathrm{~A}$ shows representative ERG responses to test flashes of increasing intensities. Both scotopic ERG a- and b-waves were markedly reduced in aged mice. This reduction was also observable from the corresponding intensity-response relations for the a-wave (Fig. $2 B$ ) and b-wave (Fig. 2C). The data were fit by hyperbolic functions (Fig. $2 B, C$; Table 3). Half-saturating light intensities $\left(I_{\mathrm{h}}\right)$ of the ERG a- and b-wave intensity-response relations in aged mice were comparable to those in adult mice $(p>0.05)$. The slope of the intensity-response relation (determined from the Hill coefficient, $n$ ) (Table 3 ) in aged mice was slightly reduced for the a-wave ( $p=0.03$ ) but somewhat increased for the b-wave ( $p=0.016)$ compared with adult animals. The reason for these age-induced slope variations is currently unclear. The observed age-related decline in both rod a- and b-wave amplitudes (twofold) was comparable to the loss of total opsin in aged mouse retinae described above. In contrast, photopic ERG a- and b-wave amplitudes were only modestly (1.3-1.5-fold, $p<0.05)$ decreased in aged mice (Fig. $2 D$ ), suggesting that age influenced cone viability and function to a lesser extent compared with rods. This observation, consistent with earlier reports (Gresh et al., 2003; Williams and Jacobs, 2007), also correlated with the unchanged photopic visual acuity and spatial contrast sensitivity in B6D2F1/J mice.

\section{Dark-adapted aged mouse rods contain very low percentage of free opsin}

To test the possible link between deterioration of rod photoreceptor function with age and presumable depletion of rhodopsin chromophore (11-cis-retinal) in aged mouse rods, we recorded families of light responses to test flashes of increasing light intensities from single rods (Fig. $3 A$ ). We found that the dark current $\left(I_{\text {dark }}\right.$, measured from saturated flash responses) was comparable in adult and aged B6D2F1/J-mouse rods (Table 4), even though the length of aged rod outer segments was slightly decreased (see previous section). Despite the significant rod photoreceptor loss in aged retinae, we had no difficulty in randomly selecting cells with a response amplitude of 15 pA or larger, indicating the presence of similar fraction of individual healthy photoreceptors in old mice. The comparable dark currents in adult and aged rods imply that the total number of opened cGMPgated channels on the plasma membrane of ROSs was unaltered with age. Consistent with that notion, the single photon response amplitudes in the two age groups were also identical (Fig. 3B, Table 4).

The half-saturating light intensity $\left(I_{1 / 2}\right)$ of 2.5-year-old mouse rods was increased by a factor of $1.5(p<0.001)$ compared with rods, respectively.
Table 3. Fitting parameters of scotopic ERG a- and b-wave intensity-response relations for adult and aged $\mathrm{B} 6 \mathrm{D} 2 \mathrm{~F} 1 / \mathrm{J}$ mice

\begin{tabular}{llll}
\hline & $A_{\max }(\mu \mathrm{V})$ & $n$ & $I_{\mathrm{h}}\left(\mathrm{cd} \cdot \mathrm{sm}^{-2}\right)$ \\
\hline a-wave & & & \\
$\quad$ 4-month-old mice $(n=7)$ & $305 \pm 11$ & $0.86 \pm 0.06$ & $0.38 \pm 0.14$ \\
$\quad$ 2.5-year-old mice $(n=7)$ & $157 \pm 12$ & $0.68 \pm 0.04$ & $0.58 \pm 0.14$ \\
$\quad p$ value & $<0.001$ & 0.03 & 0.47 \\
b-wave & & & \\
$\quad$ 4-month-old mice $(n=6)$ & $831 \pm 37$ & $0.38 \pm 0.02$ & $0.0074 \pm 0.004$ \\
2.5-year-old mice $(n=6)$ & $390 \pm 34$ & $0.41 \pm 0.04$ & $0.0065 \pm 0.001$ \\
$\quad p$ value & $<0.001$ & 0.016 & 0.34 \\
\hline
\end{tabular}

See Figure $2, B$ and $C$, for details. Values are means \pm SEM.
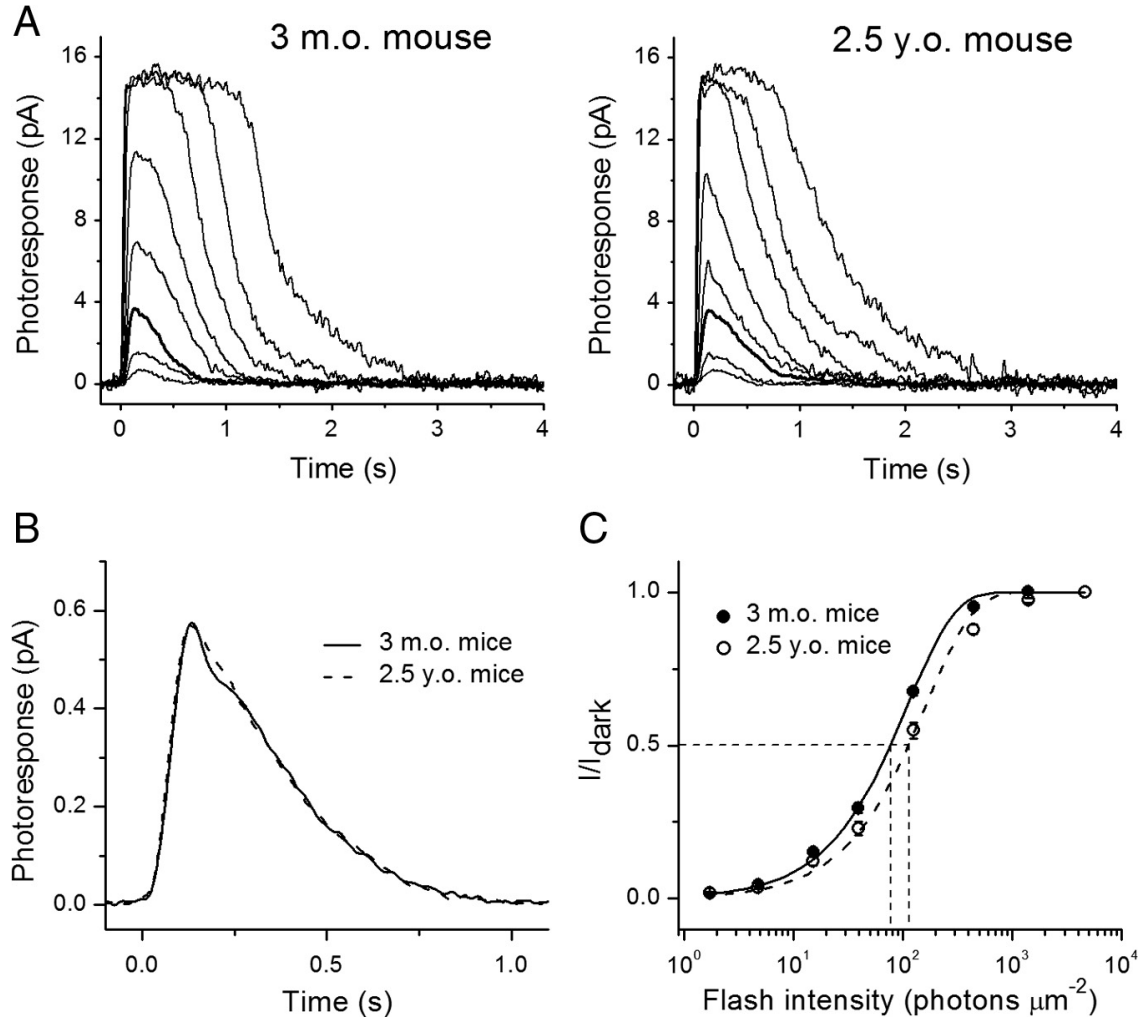

Figure 3. Analysis of single-cell responses from 3-month-old and 2.5-year-old mouse rods. $A$, Families of flash responses from representative adult- (left) and aged- (right) mouse rods. In both cases, $500 \mathrm{~nm}$ light test flashes were delivered at time 0 , with intensities of 1.7, 4.8, 15.2, 39.4, 125, 444, 1406, and 4630 photons $\mu \mathrm{m}^{-2}$. Responses to flashes delivering 15.2 photons $\mu \mathrm{m}^{-2}$ are represented by a thick black line for comparison. $\boldsymbol{B}$, Population-mean single-photon responses for adult $(0.58 \pm 0.03 \mathrm{pA}, n=$ relations. Points were fitted with saturating exponential functions that yielded half-saturated intensities $\left(I_{1 / 2}\right.$, indicated by horizontal and vertical dashed lines) of 78 and 120 photons $\mu \mathrm{m}^{-2}$ for 3-month-old (solid line) and 2.5-year-old (dashed line) mouse

adult mouse rods (Fig. 3C, Table 4), indicating a comparable decrease in sensitivity. Based on recent findings in neonatal mouse and rat rods (Luo and Yau, 2005), this decline in sensitivity is consistent with the presence of no more than $1 \%$ free opsin (devoid of 11-cis-chromophore) in aged mouse rods. Furthermore, the kinetics of dim flash responses $\left(T_{\text {integr. }}\right.$ and $\left.\tau_{\text {rec }}\right)$ that one would expect to be accelerated in the presence of a large fraction of constitutively active free opsin were not significantly different between adult and aged rods (Table 4, Fig. 3B), again consistent with the presence of negligible levels of free opsin in the aged rods. To determine directly the extent of desensitization produced by free opsin, we treated dark-adapted aged rods with 11-cis-retinal. This resulted in a slight shift in $I_{1 / 2}$ of aged rods to lower values, although the effect was rather small (1.12-fold, $p<$ 
Table 4. Parameters of single-cell responses from dark-adapted adult and aged B6D2F1/J mouse rods

\begin{tabular}{|c|c|c|c|c|c|c|}
\hline & $I_{\text {dark }}(\mathrm{pA})$ & $I_{1 / 2}\left(\mathrm{ph}_{\mu} \mu \mathrm{m}^{-2}\right)$ & $a(\mathrm{pA})$ & $T_{\text {peak }}(\mathrm{ms})$ & $T_{\text {integr. }}(\mathrm{ms})$ & $\tau_{\text {rec }}(\mathrm{ms})$ \\
\hline 4-month-old $(n=18)$ & $15.2 \pm 0.4$ & $78 \pm 4$ & $0.58 \pm 0.03$ & $150 \pm 3$ & $335 \pm 20$ & $277 \pm 14$ \\
\hline 2.5-year-old ( $n=17)$ & $16.1 \pm 0.5$ & $120 \pm 11$ & $0.57 \pm 0.04$ & $152 \pm 6$ & $308 \pm 17$ & $254 \pm 17$ \\
\hline$p$ value & $>0.05$ & $<0.001$ & $>0.05$ & $>0.05$ & $>0.05$ & $>0.05$ \\
\hline
\end{tabular}

$I_{\text {dark }}$ refers to the dark current measured from saturated responses; $I_{1 / 2}$ is the light intensity required to produce half-saturating response; $a$ is the single-photon response amplitude. Time-to-peak $\left(T_{\text {peak }}\right)$ and integration time $\left(T_{\text {integr. }}\right.$. describe responses with amplitudes $<0.2 I_{\text {dark }}$ and fell within the linear range; $\tau_{\text {rec }}$ refers to the time constant of single-exponential fit to the recovery phase of the averaged dim flash response of each individual cell. Values are means \pm SEM.

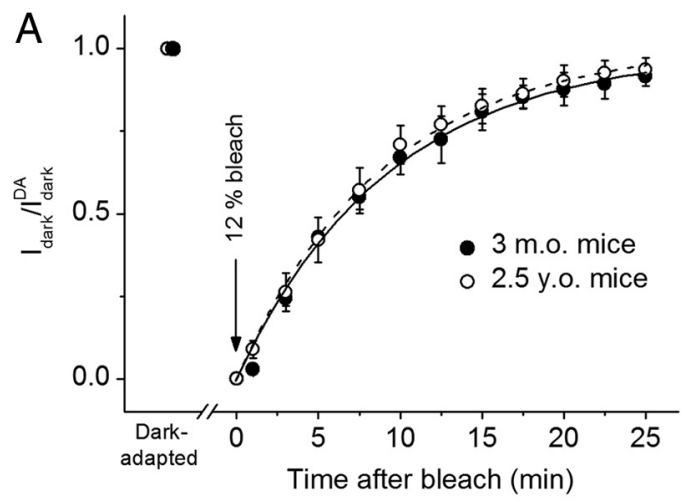

B

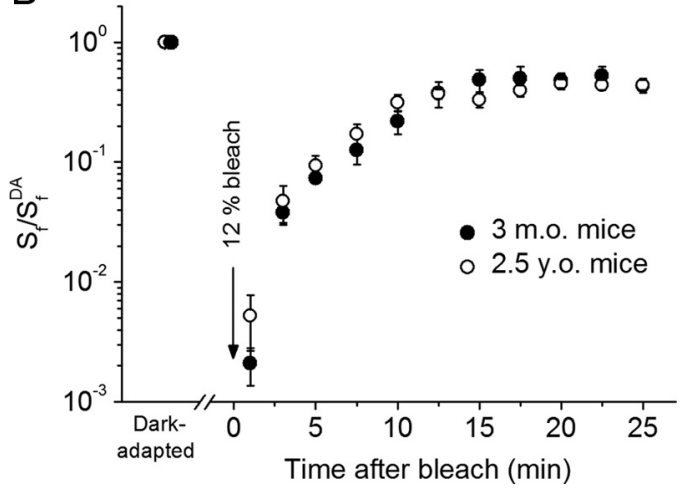

Figure 4. $\boldsymbol{A}, \boldsymbol{B}$, Recovery of dark current $\left(I_{\text {dark }} ; \boldsymbol{A}\right)$ and flash sensitivity $\left(S_{f} ; \boldsymbol{B}\right)$ after bleaching $12 \%$ of rhodopsin at time 0 in 3-month-old $(n=5)$ and 2.5 -year-old $(n=12)$ solitary mouse rods. Data were derived from suction electrode recordings. Each parameter is plotted normalized to its corresponding dark-adapted value (DA). Values are means \pm SEM. Dark current recovery in $\boldsymbol{A}$ was fitted by single-exponential functions with time constants of 9.4 and $9.0 \mathrm{~min}$ for adult (solid line) and aged (dashed line) rods, respectively.

0.05) (data not shown). This result is also consistent with a minor effect of free opsin on the function of dark-adapted aged rods.

\section{Rate of rod flash sensitivity recovery after a bleach is unaffected by age}

To directly investigate the effect of age on the function of the mouse visual cycle, we compared the recovery rates of dark current $\left(I_{\text {dark }}\right)$ and flash sensitivity $\left(S_{\mathrm{f}}\right)$ after bleaching a significant fraction $(12 \%)$ of the pigment in isolated adult and aged rods (Fig. 4). In the absence of any RPE-driven pigment regeneration, this recovery would reflect the quenching of phototransduction cascade as pigment metaproducts I-III decay to free opsin (Cornwall and Fain, 1994; Leibrock et al., 1994, 1998; Melia et al., 1997; Firsov et al., 2005, 2007). A combination of various factors contributing to this process, such as rates of rhodopsin phosphorylation and/or arrestin binding, lipid composition/properties of the disc membrane, as well as the activity of photoreceptor retinol dehydrogenase(s) toward releasing chromophore (all-transretinal), when compromised with age, would potentially affect the recovery of rods following the bleach. However, the time constants of rod current recovery in our experiments were identical in the two mouse groups ( $\sim 9 \mathrm{~min}$ ) (Fig. $4 A$ ). We also observed identical rates of postbleach recovery of flash sensitivity in the same cells (Fig. $4 \mathrm{~B}$ ). Thus, the factors listed above were not compromised as a whole in $\mathrm{B} 6 \mathrm{D} 2 \mathrm{~F} 1 / \mathrm{J}$ mouse rods during normal aging.

\section{The RPE-driven rod visual cycle operates normally in aged} mice

Finally, we compared the rates of in vivo dark adaptation (driven by recycling 11-cis-retinal in the RPE) in adult and aged animals by tracing the recovery of rod ERG a-wave amplitude and flash sensitivity after almost complete $(>90 \%)$ bleaching of the visual pigment. Under these conditions, the complete visual cycle is operational, as both photoreceptors and RPE cells are preserved and intact. In accordance with findings described above (Fig. $2 A)$, the absolute a-wave amplitude and flash sensitivity were decreased by approximately twofold in aged animals (data not shown). Surprisingly, we did not observe a difference between adult and aged mice in the recovery kinetics for a-wave amplitude (Fig. 5A) and sensitivity (Fig. 5B). Thus, the rate of the RPEdriven visual cycle was not affected by aging in $\mathrm{B} 6 \mathrm{D} 2 \mathrm{~F} 1 / \mathrm{J}$ mice. This finding implies that the visual cycle operated normally in the remaining rods in aged mouse retinae.

\section{Increased dark noise in aged rods contributes to their desensitization}

In the course of our single-cell recordings, we noticed that the dark current appeared noisier in rods from aged mice compared with those from adult animals. To investigate this further, we measured the mean cellular dark noise variance for rods from both age groups. We analyzed rod outer segment currents recorded in darkness (Fig. 6A) and calculated dark power spectra (Fig. $6 B$ ) with characteristic phototransduction noise variance at low frequencies (Rieke and Baylor, 1996; Burns et al., 2002). All studied aged rods demonstrated substantially higher (2.2-fold on average) cellular dark noise variance between 0.4 and $5 \mathrm{~Hz}$ (Fig. $6 \mathrm{~B})$. Consistent with the physiological origin of this noise, it could be eliminated by applying saturating background light (data not shown).

To determine a possible link between increased cellular noise of aged rods and their reduced sensitivity, we performed background light adaptation experiments using photoreceptors of adult mice as a standard. Rods were illuminated with a steady background light of increasing intensity and both photoreceptor sensitivity $\left(S_{\mathrm{f}}\right)$ and dark noise variance $\left(\sigma^{2}\right)$ were determined under each light condition. Steady background light photoactivating $>10$ rhodopsins per second $\left(\mathrm{R}^{*} \mathrm{~s}^{-1}\right)$ caused decrease of mouse rod sensitivity, which declined monotonically with light strength up to $\sim 5000 \mathrm{R}^{\star} \mathrm{s}^{-1}$, where rods saturated (Fig. $6 C$ ). In contrast to the pattern of rod sensitivity reduction, cellular dark noise of adult mouse rods initially increased with the number of photoactivations (up to $\sim 100 \mathrm{R}^{\star} \mathrm{s}^{-1}$ ) but then declined as the response to each photoisomerization decreased in amplitude due 

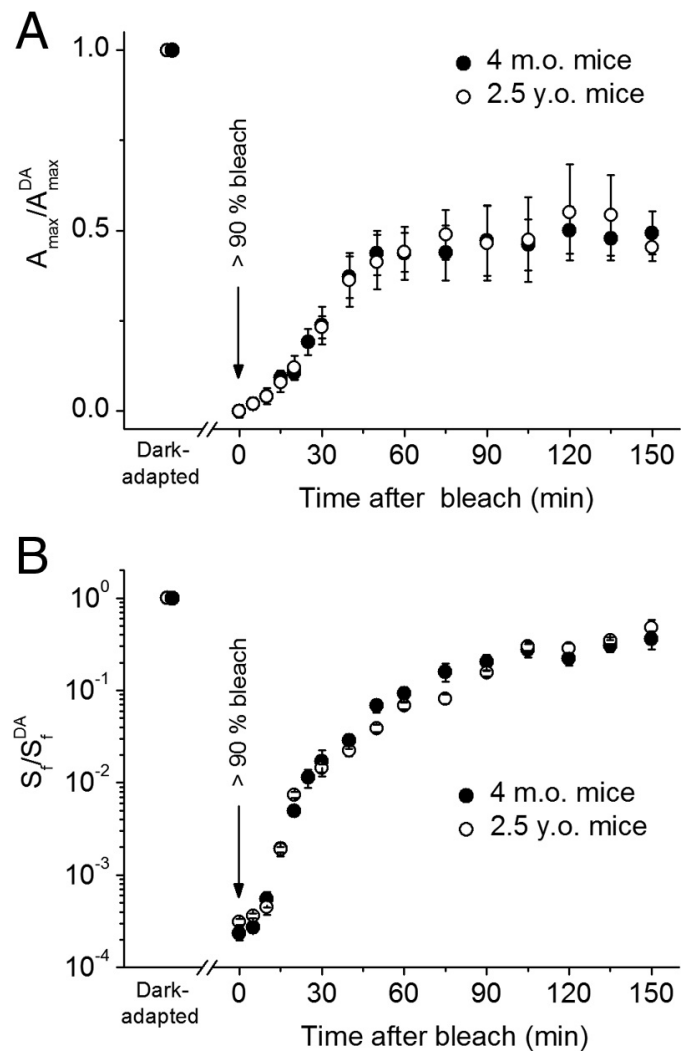

Figure 5. $\boldsymbol{A}, \boldsymbol{B}$, Recovery of ERG a-wave amplitude $\left(A_{\max } ; \boldsymbol{A}\right)$ and $E R G$ a-wave flash sensitivity $\left(S_{f ;} \boldsymbol{B}\right)$ after bleaching $>90 \%$ of rod visual pigment in 4-month-old ( $n=5$ mice) and 2.5 -yearold ( $n=4$ mice) animals. The parameters were normalized to their dark-adapted values $\left(A_{\max }{ }^{\mathrm{DA}}\right.$ and $\mathrm{S}_{\mathrm{f}}{ }^{\mathrm{DA}}$, respectively). Bleaching was achieved by 1 min illumination with bright 520 $\mathrm{nm}$ LED light at time 0 (see Materials and Methods). Data in $\boldsymbol{A}$ were corrected for the residual a-wave of $\sim 25-50 \mu \mathrm{V}$, presumably generated by M-cones, that was observed immediately after the bleach. Final levels of response recovery are 54 and $56 \%$ for adult and aged mice, respectively, and half-times of the recovery are $\sim 30 \mathrm{~min}$ in both cases (including an initial $\sim 10$ min delay). All values are means \pm SEM.

to light adaptation. A background light of $\sim 40 \mathrm{R}^{*} \mathrm{~s}^{-1}$ (Fig. 6C, vertical dashed line) induced a 2.2-fold increase in dark noise, comparable to that observed in aged rods (Fig. 6C, right ordinate). This background light also caused 1.3-fold decrease in the flash sensitivity of adult rods (Fig. 6C, left ordinate). Thus, the excess noise in aged rods would explain most ( 1.3 of 1.5 -fold) of the reduction in their sensitivity, with the remaining 1.15 -fold caused by other mechanism(s).

Finally, to determine whether the source of increased dark noise in aged rods originated from the presence of a small fraction of unregenerated free opsin, we bleached $1 \%$ of rhodopsin in rods from adult mice and directly compared the changes in both noise and sensitivity $\left(I_{1 / 2}\right)$ caused by the bleach. Measurements were performed after a 10-15 min period of dark adaptation following the bleach, to allow rhodopsin metaproducts to release their alltrans-chromophore and decay into free apo-protein. This period was also sufficient to allow the dark current to recover completely. Notably, we did not observe an increase of noise level in the presence of $1 \%$ fraction of naked opsin (Fig. 6D). On the other hand, bleaching $1 \%$ rhodopsin caused only a $\sim 1.12$-fold desensitization of adult-mouse rods $(p<0.05)$ (Fig. $6 E$ ), thus accounting only for a small fraction of the $\sim 1.5$-fold total desensitization found in dark-adapted aged photoreceptors (Fig. 3C). In the opposite experiment, treatment of dark-adapted aged rods with exogenous 11-cis-retinal to regenerate any residual free op- sin did not result in significant reduction of the noise (data not shown), yet restored their $I_{1 / 2}$ to the same extent (1.12-fold, $p<$ 0.05) (data not shown), thus indicating that the major source of noise in aged rods was not free opsin and was presumably downstream from the visual pigment.

\section{Discussion}

The performance of our visual system deteriorates with age. Essential parts of such age-related modifications proceed within both retina and the adjacent RPE (for review, see Jackson et al., 2002; Bonnel et al., 2003). Previous studies have shown that in humans, $20-30 \%$ of retina rod photoreceptors can be lost due to normal aging (Curcio et al., 1993; Panda-Jonas et al., 1995; Curcio, 2001), presumably by apoptosis (Lambooij et al., 2000). In contrast, the number of cone photoreceptors remains relatively stable throughout adulthood and even in early age-related maculopathy (ARM) (Gao and Hollyfield, 1992; Curcio et al., 2000), at least until very advanced age when cone density also declines (Feeney-Burns et al., 1990). The preferential susceptibility of rods in aging and early ARM highlights the importance of understanding the age-induced physiological alterations in these photoreceptors. To establish the mouse as a model for studying the physiological mechanisms that underlie age-related deterioration of vision, we sought to characterize how mouse rod photoreceptor function is altered by age. We chose the pigmented hybrid B6D2F1/J mouse strain, as it has improved longevity compared with the traditionally used C57BL/6 strain (Turturro et al., 1999; Nadon, 2006). This allowed us to conduct experiments with up to 2.5-year-old animals, near the end of their lifespan.

Although there have been a few recent behavioral studies addressing the effects of age on mouse visual performance, they were mostly limited either to photopic conditions (Van Alphen et al., 2009) or dim-light conditions (Wong and Brown, 2007). Our behavioral experiments were designed to carefully control any lights reaching the dark-adapted animal by using surrounding neutral density filters and infrared illumination. We found that in aged mice, the rod-driven scotopic visual thresholds for detectable optomotor responses defining both visual acuity and spatial contrast sensitivity were approximately two times lower compared with adult mice (Table 1).

The observed deterioration of scotopic vision in aged mice could potentially be driven by two mechanisms. There could be significant retinal degeneration, including reduction in the number of rod photoreceptors and their pigment content and/or changes in rod morphology, as well as possible alterations in downstream retina neurons and neuronal pathways. Alternatively, the physiological properties of rods might be compromised during normal aging. Despite well established age-related loss of rod photoreceptors in retinae of humans and albino mice, it is still controversial whether similar changes occur in pigmented rodents (Trachimowicz et al., 1981; Li et al., 2001; Gresh et al., 2003; Cunea and Jeffery, 2007; Feng et al., 2007). Our morphological results demonstrate the loss of $\sim 40 \%$ of rod photoreceptor material (Fig. 1, Table 2). These results are in line with the observed decline in total opsin content expressed per whole retina (Table 2) and, equally important, with similar age-dependent decrease of both ERG a- and b-waves (Fig. 2). Such age-related decline of the ERG components has been observed in many previous studies in both humans (Weleber, 1981; Birch et al., 1992, 2002) and mice (Pugh et al., 1998; Li et al., 2001; Gresh et al., 2003). Thus, our results indicate that retinal degeneration and photoreceptor loss contribute to the deterioration of scotopic vision in aged mice. 
A 3 m.o. mice

2.5 y.o. mice
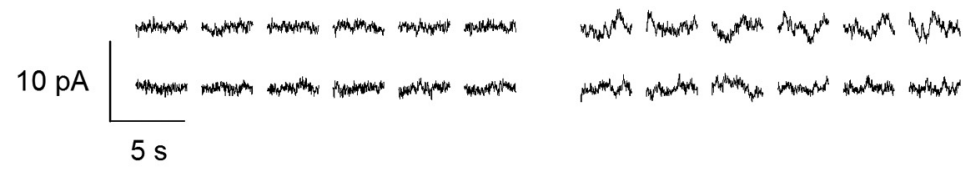

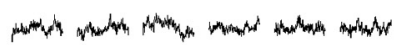

B

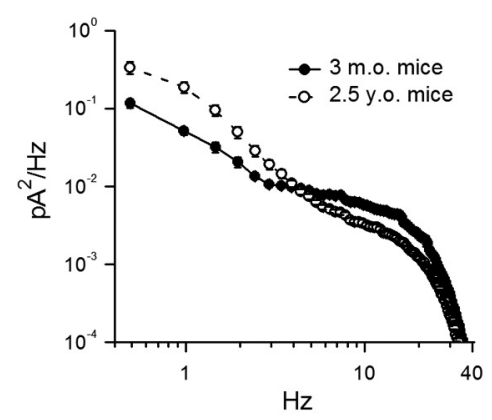

C

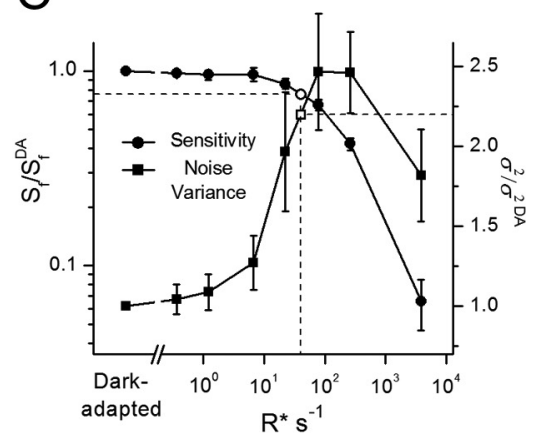

E

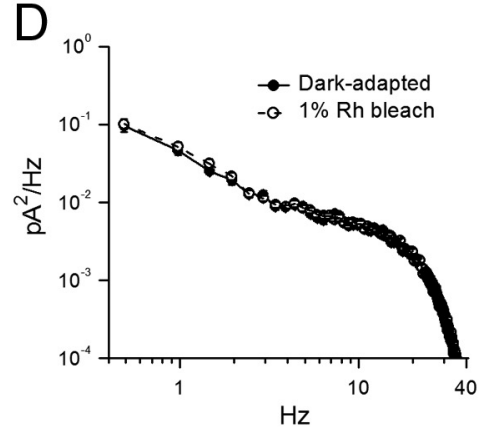

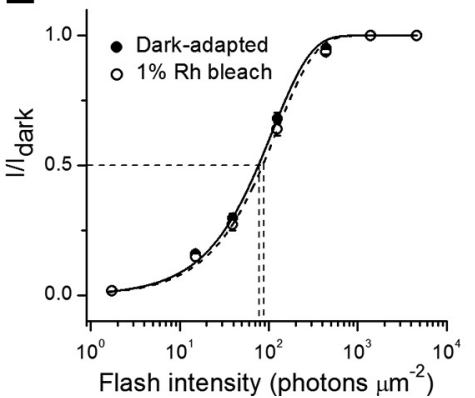

Figure 6. Cellular dark noise in 3-month-old and 2.5-year-old mouse rods. $A$, Representative $3.5 \mathrm{~s}$ current recordings from two 3-month-old (left) and tw0 2.5-year-old (right) rods in darkness. $\boldsymbol{B}$, Mean dark power spectra revealed a substantial increase in the low-frequency cellular dark noise in aged rods. Averaged cellular dark noise variances $\left(\sigma^{2}, 0.4-10 \mathrm{~Hz}\right)$ are $0.175 \pm 0.015 \mathrm{pA}^{2}$ $(n=18)$ for adult rods and $0.393 \pm 0.057 \mathrm{pA}^{2}(n=17)$ for aged rods. C, Correlation between flash sensitivity $\left(S_{f}\right.$ left $y$-axis, $n=$ 16) and normalized cellular dark noise variance $\left(\sigma^{2}\right.$, right $y$-axis, $\left.n=16\right)$ as a function of background light intensity in adultmouse rods. Background light of $40 \mathrm{R}^{*} \mathrm{~s}^{-1}$ (vertical dashed line) caused a 2.2-fold increase in the cellular noise level and accompanying 1.3-fold decrease in rod sensitivity. DA indicates parameters in dark adapted-conditions. $\boldsymbol{D}$, Mean dark noise power spectra of rods from adult mice in dark-adapted state and then after bleaching $1 \%$ of their visual pigment $(n=15)$. $\sigma^{2}$ values $\left(0.4-10 \mathrm{~Hz}\right.$ ) are $0.130 \pm 0.010 \mathrm{pA}^{2}$ (dark-adapted state) and $0.141 \pm 0.011 \mathrm{pA}^{2}$ (after bleaching) $(p=0.49)$. , Normalized averaged intensity-response relations for the cells in $\boldsymbol{D}$. Points were fitted with saturating exponential functions that yielded $I_{1 / 2}$ values (thin dashed lines) of $76 \pm 3$ and $85 \pm 4$ photons $\mu \mathrm{m}^{-2}$ for 3-month-old dark-adapted mouse rods (solid line) and the same cells following $1 \%$ rhodopsin bleach (dashed line), respectively $(p<0.05)$. All values are means \pm SEM (smaller than symbol size for most data points). Rh, Rhodopsin.

Interestingly, we did not observe a statistically significant shift of a- and b-wave intensity-response relations to brighter light intensities in older mice (Table 3 ). This suggests that the fraction of free opsin (devoid of its chromophore 11-cis-retinal), which, if accumulated to significant levels, would continuously activate transducin, trigger the phototransduction cascade, and desensitize rods (Cornwall et al., 1994; Fan et al., 2005; Kefalov et al., 2005), was similar in dark-adapted photoreceptors of both adult and aged mice. However, standard full-field ERG recordings do not allow investigating this question quantitatively. Instead, this issue can be addressed with suction recordings and the direct measurement of sensitivity and response kinetics in solitary rods. Using this technique, we found that sensitivity of dark-adapted aged mouse rods (as measured from $I_{1 / 2}$ ) was decreased by 1.5-fold compared with adult animals (Fig. $3 C$ ). However, due to the nonlinearity between sensitivity and free opsin content (Fan et al., 2005; Luo and Yau, 2005; Kefalov et al., 2005), this desensitization corresponds to only a minor fraction (not exceeding 1\%) of opsin devoid

of chromophore (Luo and Yau, 2005). The identical amplitude and kinetics of singlephoton response in adult and aged animals (Fig. 3B, Table 4) further support the insignificant effect of free opsin on rod phototransduction. In addition, these data demonstrate that both activation and inactivation of the phototransduction cascade proceed normally in aged mouse rods. This is consistent with the absence of impact of aging on the leading edge of human scotopic ERG a-wave (Jackson et al., 2004).

Jackson and colleagues have recently reported that aging somewhat slowed the inactivation phase of the human rod a-wave at saturating light of moderate intensities (Jackson et al., 2006). A critical step in photoresponse termination is the inactivation of transducin/PDE complex by RGS9-1 (Krispel et al., 2006). Our results showing identical dim-flash response kinetics in adult and aged rods argue against significant effect of aging on this step in B6D2F1/J mouse rods. Further, the nearly identical rates of recovery of rod dark current and flash sensitivity after bleaching $12 \%$ of rod pigment in adult and aged photoreceptors (Fig. 4) indicate similar rates of decay of long-lived rhodopsin photointermediates and appearance of free opsin. Nonetheless, a thorough comparison between mouse and human cases would be required to settle this issue.

A hypothesis for age-related retinoid deficiency caused by the limited availability of 11-cis-retinal in human retinae has been suggested (Jackson et al., 2002) to account for the substantial delay of rod dark adaptation observed in elder patients (Steinmetz et al., 1993; Jackson et al., 1999). To our knowledge, no quantitative measurements of the impact of aging on dark adaptation and the visual cycle have been performed in mouse models. In the present study, we investigated the validity of the retinoid deficiency hypothesis for B6D2F1/J mice. Surprisingly, the rate of rod dark adaptation was unaffected by age (Fig. 5), indicating normal function of the visual cycle in the surviving rods of 2.5-year-old mice. This is also in line with our finding from single-cell recordings that only a small fraction of free opsin is present in aged-mouse rods. Nevertheless, care should be taken when extrapolating our results to the situation in different mouse strains and humans. Among the major reasons for such a caution would be genetic polymorphisms in visual cycle genes between mouse strains, a considerably faster absolute rate of dark adaptation in humans compared with mice, and possible differences in expression levels or activity of various visual cycle proteins in the two species (for review, see Lamb and Pugh, 2004).

Finally, we observed a surprising increase in the lowfrequency cellular dark noise of aged mouse rods compared with rods from adult animals (Fig. 6). The mechanism generating this noise is currently unclear. Most of this noise was likely not pro- 
duced by free opsin, as it could neither be reduced by a treatment of aged rods with exogenous 11-cis-retinal nor be induced by bleaching $1 \%$ of rhodopsin in rods from adult animals (Fig. $6 D$ ). A potential source of this low-frequency noise component in aged rods could be fluctuations in the rate of cGMP hydrolysis due to spontaneous activation of the phototransduction cascade effector enzyme, cGMP phosphodiesterase (Rieke and Baylor, 1996), which is downstream from the visual pigment. Notably, background light-induced noise equivalent to that observed in the aged mouse rods reduced flash sensitivity of adult rod by 1.3 -fold. This may indicate that only the remaining 1.15 -fold desensitization of aged photoreceptors (of their 1.5-fold total desensitization observed from single-cell recordings; see above) could be attributed to free apo-protein. This estimation is in agreement with the observed 1.12-fold increase of sensitivity of aged rods induced by treatment with exogenous 11-cischromophore, as well as with the same 1.12-fold desensitization of adult rods caused by bleaching $1 \%$ of their pigment (Fig. $6 E$ ). Thus, the main source of desensitization in dark-adapted aged mouse rods appears to originate in their increased cellular noise.

\section{References}

Adams AJ, Wong LS, Wong L, Gould B (1988) Visual acuity changes with age: some new perspectives. Am J Optom Physiol Opt 65:403-406.

Baylor DA, Lamb TD, Yau KW (1979) Responses of retinal rods to single photons. J Physiol 288:613-634.

Birch DG, Anderson JL (1992) Standardized full-field electroretinography: normal values and their variation with age. Arch Ophthalmol 110:1571-1576.

Birch DG, Hood DC, Locke KG, Hoffman DR, Tzekov RT (2002) Quantitative electroretinogram measures of phototransduction in cone and rod photoreceptors: normal aging, progression with disease, and test-retest variability. Arch Ophthalmol 120:1045-1051.

Bonnel S, Mohand-Said S, Sahel JA (2003) The aging of the retina. Exp Gerontol 38:825-831.

Burns ME, Mendez A, Chen J, Baylor DA (2002) Dynamics of cyclic GMP synthesis in retinal rods. Neuron 36:81-91.

Carter-Dawson LD, LaVail MM (1979) Rods and cones in the mouse retina. I. Structural analysis using light and electron microscopy. J Comp Neurol 188:245-262.

Cornwall MC, Fain GL (1994) Bleached pigment activates transduction in isolated rods of the salamander retina. J Physiol 480:261-279.

Cunea A, Jeffery G (2007) The ageing photoreceptor. Vis Neurosci 24:151-155.

Curcio CA (2001) Photoreceptor topography in ageing and age-related maculopathy. Eye 15:376-383.

Curcio CA, Millican CL, Allen KA, Kalina RE (1993) Aging of the human photoreceptor mosaic: evidence for selective vulnerability of rods in central retina. Invest Ophthalmol Vis Sci 34:3278-3296.

Curcio CA, Owsley C, Jackson GR (2000) Spare the rods, save the cones in aging and age-related maculopathy. Invest Ophthalmol Vis Sci 41:2015-2018.

Daniele LL, Lillo C, Lyubarsky AL, Nikonov SS, Philp N, Mears AJ, Swaroop A, Williams DS, Pugh EN Jr (2005) Cone-like morphological, molecular, and electrophysiological features of the photoreceptors of the $\mathrm{Nrl}$ knockout mouse. Invest Ophthalmol Vis Sci 46:2156-2167.

Dartnall HJ (1968) The photosensitivities of visual pigments in the presence of hydroxylamine. Vision Res 8:339-358.

Fan J, Woodruff ML, Cilluffo MC, Crouch RK, Fain GL (2005) Opsin activation of transduction in the rods of dark-reared Rpe65 knockout mice. J Physiol 568:83-95.

Feeney-Burns L, Burns RP, Gao CL (1990) Age-related macular changes in humans over 90 years old. Am J Ophthalmol 109:265-278.

Feng L, Sun Z, Han H, Zhou Y, Zhang M (2007) No age-related cell loss in three retinal nuclear layers of the Long-Evans rat. Vis Neurosci 24:799-803.

Firsov ML, Kolesnikov AV, Golobokova EY, Govardovskii VI (2005) Two realms of dark adaptation. Vision Res 45:147-151.

Firsov ML, Golobokova EY, Govardovskii VI (2007) Two-stage quenching of cone phototransduction cascade. Sens Syst 21:55-59.
Fulton AB, Rushton WA (1978) The human rod ERG: correlation with psychophysical responses in light and dark adaptation. Vision Res 18:793-800.

Gao H, Hollyfield JG (1992) Aging of the human retina: differential loss of neurons and retinal pigment epithelial cells. Invest Ophthalmol Vis Sci 33:1-17.

Gresh J, Goletz PW, Crouch RK, Rohrer B (2003) Structure-function analysis of rods and cones in juvenile, adult, and aged C57bl/6 and BALB/c mice. Vis Neurosci 20:211-220.

Haegerstrom-Portnoy G, Schneck ME, Brabyn JA (1999) Seeing into old age: vision function beyond acuity. Optom Vis Sci 76:141-158.

Jackson GR, Owsley C (2000) Scotopic sensitivity during adulthood. Vision Res 40:2467-2473.

Jackson GR, Owsley C, Cordle EP, Finley CD (1998) Aging and scotopic sensitivity. Vision Res 38:3655-3662.

Jackson GR, Owsley C, McGwin G Jr (1999) Aging and dark adaptation. Vision Res 39:3975-3982.

Jackson GR, Owsley C, Curcio CA (2002) Photoreceptor degeneration and dysfunction in aging and age-related maculopathy. Ageing Res Rev 1:381-396.

Jackson GR, McGwin G Jr, Phillips JM, Klein R, Owsley C (2004) Impact of aging and age-related maculopathy on activation of the a-wave of the rod-mediated electroretinogram. Invest Ophthalmol Vis Sci 45:3271-3278.

Jackson GR, McGwin G Jr, Phillips JM, Klein R, Owsley C (2006) Impact of aging and age-related maculopathy on inactivation of the a-wave of the rod-mediated electroretinogram. Vision Res 46:1422-1431.

Kefalov VJ, Estevez ME, Kono M, Goletz PW, Crouch RK, Cornwall MC, Yau KW (2005) Breaking the covalent bond: a pigment property that contributes to desensitization in cones. Neuron 46:879-890.

Krispel CM, Chen D, Melling N, Chen YJ, Martemyanov KA, Quillinan N, Arshavsky VY, Wensel TG, Chen CK, Burns ME (2006) RGS expression rate-limits recovery of rod photoresponses. Neuron 51:409-416.

Lamb TD, Pugh EN Jr (2004) Dark adaptation and the retinoid cycle of vision. Prog Retin Eye Res 23:307-380.

Lambooij AC, Kliffen M, Kuijpers RW, Houtsmuller AB, Broerse JJ, Mooy CM (2000) Apoptosis is present in the primate macula at all ages. Graefes Arch Clin Exp Ophthalmol 238:508-514.

Leibrock CS, Reuter T, Lamb TD (1994) Dark adaptation of toad rod photoreceptors following small bleaches. Vision Res 34:2787-2800.

Leibrock CS, Reuter T, Lamb TD (1998) Molecular basis of dark adaptation in rod photoreceptors. Eye (Lond) 12:511-520.

Li C, Cheng M, Yang H, Peachey NS, Naash MI (2001) Age-related changes in the mouse outer retina. Optom Vis Sci 78:425-430.

Luo DG, Yau KW (2005) Rod sensitivity of neonatal mouse and rat. J Gen Physiol 126:263-269.

Melia TJ Jr, Cowan CW, Angleson JK, Wensel TG (1997) A comparison of the efficiency of $\mathrm{G}$ protein activation by ligand-free and light-activated forms of rhodopsin. Biophys J 73:3182-3191.

Nadon NL (2006) Exploiting the rodent model for studies on the pharmacology of lifespan extension. Aging Cell 5:9-15.

Panda-Jonas S, Jonas JB, Jakobczyk-Zmija M (1995) Retinal photoreceptor density decreases with age. Ophthalmology 102:1853-1859.

Prusky GT, Alam NM, Beekman S, Douglas RM (2004) Rapid quantification of adult and developing mouse spatial vision using a virtual optomotor system. Invest Ophthalmol Vis Sci 45:4611-4616.

Pugh EN Jr, Falsini BF, Lyubarsky AL (1998) The origin of the major rodand cone-driven components of the rodent electroretinogram, and the effect of age and light-rearing history on the magnitudes of these components. In: Photostasis and related topics (Williams TP, Thistle AB, eds), pp. 93-128. New York: Plenum.

Rieke F, Baylor DA (1996) Molecular origin of continuous dark noise in rod photoreceptors. Biophys J 71:2553-2572.

Rohrer B, LaVail MM, Jones KR, Reichardt LF (2001) Neurotrophin receptor TrkB activation is not required for the postnatal survival of retinal ganglion cells in vivo. Exp Neurol 172:81-91.

Rohrer B, Goletz P, Znoiko S, Ablonczy Z, Ma JX, Redmond TM, Crouch RK (2003) Correlation of regenerable opsin with rod ERG signal in Rpe $65^{-1-}$ mice during development and aging. Invest Ophthalmol Vis Sci 44:310-315.

Shi G, Yau KW, Chen J, Kefalov VJ (2007) Signaling properties of a short- 
wave cone visual pigment and its role in phototransduction. J Neurosci 27:10084-10093.

Sloane ME, Owsley C, Jackson CA (1988) Aging and luminance-adaptation effects on spatial contrast sensitivity. J Opt Soc Am A 5:2181-2190.

Steinmetz RL, Haimovici R, Jubb C, Fitzke FW, Bird AC (1993) Symptomatic abnormalities of dark adaptation in patients with age-related Bruch's membrane change. Br J Ophthalmol 77:549-554.

Thompson DA, Gal A (2003) Vitamin A metabolism in the retinal pigment epithelium: genes, mutations, and diseases. Prog Retin Eye Res 22: 683-703.

Trachimowicz RA, Fisher LJ, Hinds JW (1981) Preservation of retinal structure in aged pigmented mice. Neurobiol Aging 2:133-141.

Turturro A, Witt WW, Lewis S, Hass BS, Lipman RD, Hart RW (1999) Growth curves and survival characteristics of the animals used in the Biomarkers of Aging Program. J Gerontol A Biol Sci Med Sci 54: B492-501.

Umino Y, Solessio E, Barlow RB (2008) Speed, spatial, and temporal tuning of rod and cone vision in mouse. J Neurosci 28:189-198. van Alphen B, Winkelman BH, Frens MA (2009) Age- and sex-related differences in contrast sensitivity in C57BL/6 mice. Invest Ophthalmol Vis Sci 50:2451-2458.

Wald G, Brown PK (1958) Human rhodopsin. Science 127:222-226.

Weleber RG (1981) The effect of age on human cone and rod ganzfeld electroretinograms. Invest Ophthalmol Vis Sci 20:392-399.

Wen XH, Shen L, Brush RS, Michaud N, Al-Ubaidi MR, Gurevich VV, Hamm HE, Lem J, Dibenedetto E, Anderson RE, Makino CL (2009) Overexpression of rhodopsin alters the structure and photoresponse of rod photoreceptors. Biophys J 96:939-950.

Williams GA, Jacobs GH (2007) Cone-based vision in the aging mouse. Vision Res 47:2037-2046.

Wong AA, Brown RE (2007) Age-related changes in visual acuity, learning and memory in $\mathrm{C} 57 \mathrm{BL} / 6 \mathrm{~J}$ and $\mathrm{DBA} / 2 \mathrm{~J}$ mice. Neurobiol Aging 28: 1577-1593.

Woodruff ML, Lem J, Fain GL (2004) Early receptor current of wild-type and transducin knock-out mice: photosensitivity and light-induced $\mathrm{Ca}^{2+}$ release. J Physiol 557:821-828. 